\title{
Accelerated Aging of EPDM And Butyl Elastomers
}

Federal Manufacturing \& Technologies

\author{
M. H. Wilson \\ KCP-613-5806 \\ Published June 1996
}

Final Report

Approved for public release; distribution is unlimited.

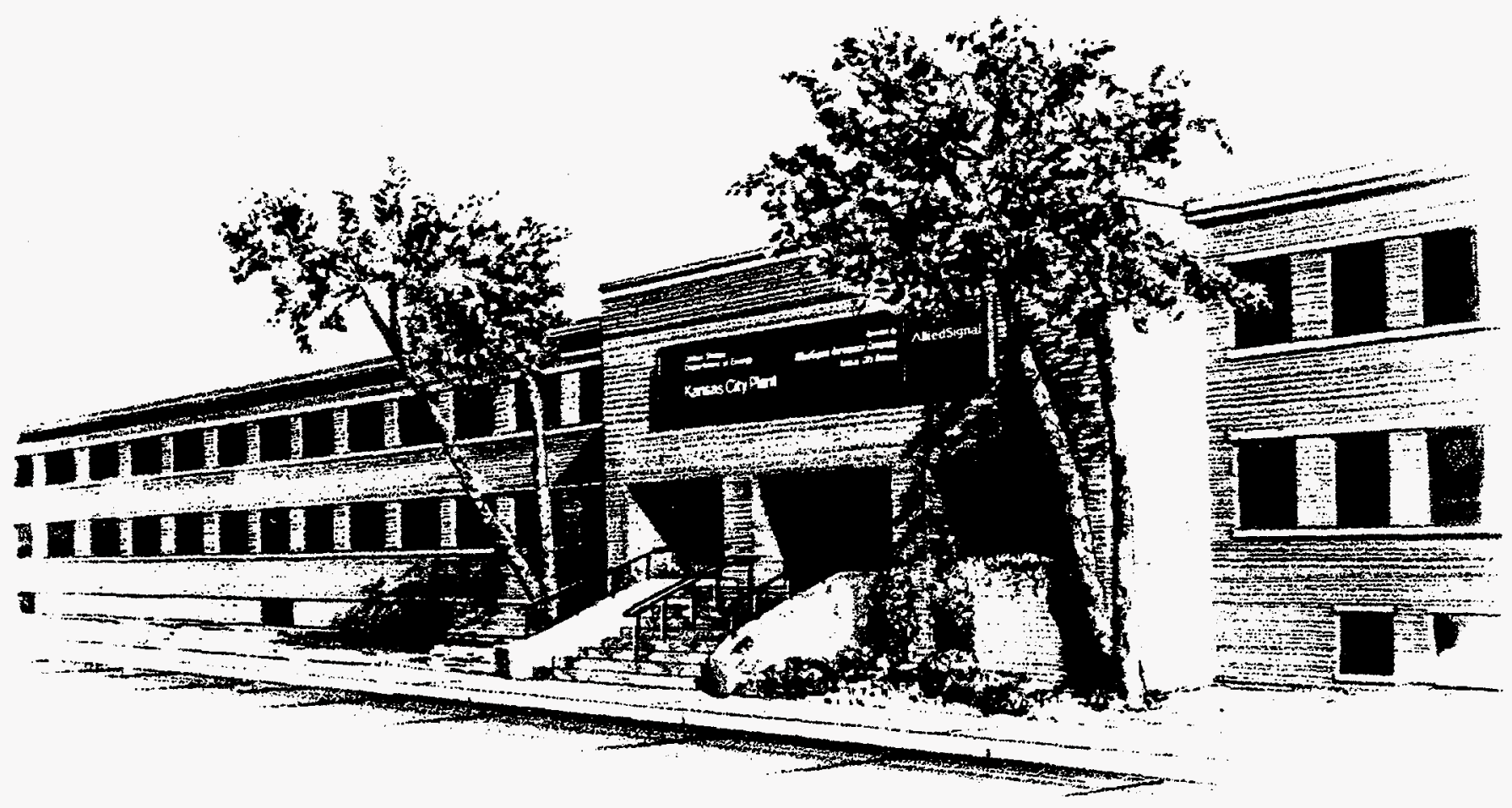

Prepared Under Contract Number DE-AC04-76-DP00613 for the United States Department of Energy

AlliedSignal DISTRBBUTON OF THIS DOCUMENT IS UNLMITED 


\section{DISCLAIMER}

This report was prepared as an account of work sponsored by an agency of the United States Government. Neither the United States Government nor any agency thereof, nor any of their employees, makes any warranty, express or implied, or assumes any legal liability or responsibility for the accuracy, completeness, or usefulness of any information, apparatus, product, or process disclosed, or represents that its use would not infringe privately owned rights. The views and opinions of authors expressed herein do not necessarily state or reflect those of the United States Government or any agency thereof.

All data prepared, analyzed, and presented has been developed in a specific context of work and was prepared for internal evaluation and use pursuant to that work authorized under the referenced contract. Reference herein to any specific commercial product, process or service by trade name, trademark, manufacturer, or otherwise, does not necessarily constitute or imply its endorsement, recommendation, or favoring by the United States Government, any agency thereof or AlliedSignal Inc.

Printed in the United States of America.

This report has been reproduced from the best available copy.

Available to DOE and DOE contractors from the Office of Scientific and Technical Information, P. O. Box 62, Oak Ridge, Tennessee 37831; prices available from (615) 576-8401, FTS 626-8401.

Available to the public from the National Technical Information Service, U. S. Department of Commerce, 5285 Port Royal Rd., Springfield, Virginia 22161.

A prime contractor with the United States Department of Energy under Contract Number DE-AC04-76-DP00613.
AlliedSignal Inc. Federal Manufacturing \& Technologies P. O. Box 419159 Kansas City, Missouri 64141-6159 
KCP-613-5806

Distribution Category UC-706

Approved for public release; distribution is unlimited.

\section{ACCELERATED AGING OF EPDM AND BUTYL ELASTOMERS}

M. H. Wilson

Published June 1996

Final Report

M. H. Wilson, Project Leader

Project Team:
A. V. May
H. C. May
H. M. Smith 

CONTENTS

Section

Page

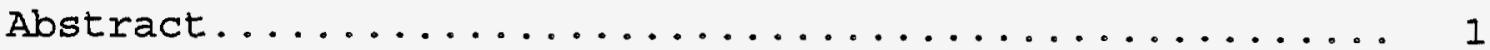

Summary ........................... 2

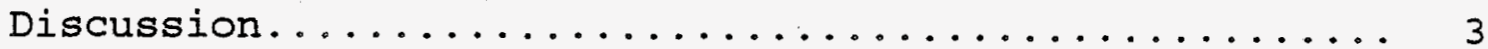

Scope and Purpose..................... 3

Prior work $\ldots \ldots \ldots \ldots \ldots \ldots \ldots \ldots \ldots \ldots \ldots \ldots \ldots \ldots \ldots \ldots$

Activity $\ldots \ldots \ldots \ldots \ldots \ldots \ldots \ldots \ldots \ldots \ldots \ldots \ldots \ldots \ldots \ldots \ldots$

Postcure Optimization Study.............. 3

Stress Relaxation Study................ 7

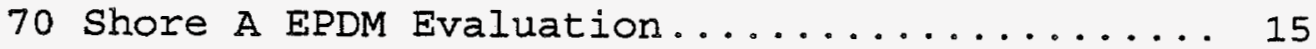

Stress Relaxation of the 70 Shore A EPDM...... 15

Accomplishments ...................... 16

Appendix. Development of EPDM Compound by the

University of Akron ...................... 19 


\section{ILLUSTRATIONS}

Figure

Page

1

Compression Set Percent Versus Postcure Time of Slabs Press-Cured 10 Minutes at $177^{\circ} \mathrm{C}$

Effect on Extractables With Press-Cure and Postcure Conditions. With Press-Cure and

Weight Percent Swell in Toluene Versus Postcure Time of Slabs Press-Cured 10 Minutes at $177^{\circ} \mathrm{C}$. . . . . .

Compression Stress Relaxation Fixture (R11577-01). . . . . . . . . . . .

Force Measuring Instrument With Fixture Ready to Be Measured (R11577-02) . . . . . . .

Stress Relaxation of Butyl and EPDM After Aging at $70^{\circ} \mathrm{C}$. . . . . . . . . . . . . .

Stress Relaxation of Butyl and EPDM After Aging at $80^{\circ} \mathrm{C}$. . . . . . . . . . . . .

Stress Relaxation of Butyl, the Original EPDM Formulation, and the 70 Shore A EPDM

Formulation After Aging at $80^{\circ} \mathrm{C}$. . . . . . 
TABLES

Number

Page

1

EPDM Formulation, SS384725 . . . . . . . .

Effects of Air Versus Vacuum Postcure. . . .

Physical Properties Before and After a Postcure of 2 Hours at $182^{\circ} \mathrm{C}$ in Air. ...

Stress Relaxation of Intermittent and Continuously Aged Butyl and EPDM Expressed as a Percent of Initial Stress . . . . . . .

Compression Set of Intermittent and

Continuously Aged Butyl and EPDM After

Stress Relaxation Testing. . . . . . . . 15

70 Shore A EPDM Formulation. . . . . . .

Physical Properties of 70 Shore A EPDM 

This study was composed of three parts: a postcure study to optimize final properties of an ethylene-propylene-diene. (EPDM) formulation, an accelerated aging study to compare the stress relaxation behavior of a butyl and an EPDM elastomer under compression, and a cursory evaluation of a new 70 Shore A EPDM. The optimum postcure for the EPDM was found to be 2 to 4 hours at $182^{\circ} \mathrm{C}$ in a vacuum. The EPDM was also shown to have superior aging characteristics compared to the butyl and is recommended for use instead of the butyl material. The physical properties for new 70 Shore A EPDM are satisfactory, and the stress relaxation behavior was only slightly inferior to the other EPDM. 
SUMMARY

This study was composed of three parts: a postcure study to optimize final properties, an accelerated aging study to compare the stress relaxation behavior of two elastomers under compression, and a cursory evaluation of a new 70 shore $A$ ethylene-propylene-diene (EPDM) supplied by the University of Akron (Akron, $\mathrm{OH}$ ). The materials tested for the postcure and accelerated aging studies were a butyl and an EPDM elastomer to be used for O-rings on a-weapon assembly. The butyl compound was B612-70, which is a proprietary formulation from Parker Seal Group, O-Ring Division, and the EPDM formulation tested was SS384725. The optimum postcure for the EPDM was found to be 2 to 4 hours at $182^{\circ} \mathrm{C}$ in a vacuum, and accelerated compression stress relaxation testing showed the EPDM to be far superior when compared with the butyl material.

The postcure study evaluated changes in certain physical properties, solvent swell, and extractables after an air or vacuum postcure at $182^{\circ} \mathrm{C}$. Postcuring is recommended because of the improvement in compression set to values lower than 10 percent after 70 hours at $125^{\circ} \mathrm{C}$. Postcure times longer than 4 hours did not improve properties and may be detrimental, especially in air. Also, postcuring in a vacuum is preferred in order to achieve optimum properties.

Comparing the accelerated compression stress relaxation behavior is the most appropriate method to determine which material will better meet the 0 -ring service life requirement of 20 to 25 years. Stress relaxation testing was performed at 70 and $80^{\circ} \mathrm{C}$ for a maximum of 616 days. To determine whether the method of removing the samples from the oven for measurement adversely affected the stress relaxation behavior, some samples were only measured at the end of the aging period. Removing the samples from the oven for measurement caused no significant difference in stress relaxation behavior from samples that were allowed to remain in the oven continuously. The EPDM was shown to have superior aging characteristics compared to the butyl and is recommended for use instead of the butyl material.

A 70 Shore A durometer EPDM originally requested from the University of Akron was finally supplied for evaluation. The lower durometer was achieved by adding a small amount of polybutadiene rubber and by reducing the level of curatives. Physical properties for this compound are satisfactory, and cursory stress relaxation results are only slightly inferior to SS384725. This new formulation represents a promising lower durometer rubber that would require further characterization before use. 


\section{DISCUSSION}

\section{SCOPE AND PURPOSE}

The purpose of this project was to optimize postcure conditions on a new ethylene-propylene-diene (EPDM) elastomer formulation, SS384725, and to compare the accelerated compression stress relaxation behavior between the new EPDM and a butyl elastomer that is specified for 0-rings on a weapon assembly. A new 70 Shore A EPDM from the University of Akron also required a cursory evaluation for comparison with the other EPDMs jointly developed with them. Butyl has been historically specified because of its low permeability; however, excessive compression set measurements from field return units show the butyl to have poor aging characteristics. Accelerated compression stress relaxation testing is the most appropriate method to determine which material will better meet the 0-ring service life requirement of 20 to 25 years.

\section{PRIOR WORK}

The EPDM elastomer tested in this study was developed under another project: Improved EPDM Elastomer Seal Formulation.

\section{ACTIVITY}

This study was composed of three parts: a postcure study to optimize final properties, an accelerated aging study to compare the stress relaxation behavior of two elastomers under compression, and a cursory evaluation of a new 70 shore A EPDM supplied by the University of Akron. The materials tested for the postcure and accelerated aging studies were a butyl and an EPDM elastomer. The butyl compound was B612-70, which is a proprietary formulation from Parker Seal Group, 0-Ring Division. Table 1 contains the EPDM formulation tested, SS384725, which was developed and mixed at the University of Akron (given in parts per hundred of rubber [PHR]).

\section{Postcure Optimization Study}

The EPDM batch was mixed at Akron and was molded 10 minutes at $177^{\circ} \mathrm{C}$ at Allied-Signal Inc., Kansas City Division (KCD), into approximately 6 by 6 by 0.075 inch test slabs. The press-cure conditions were established after running an oscillating disc rheometer (ODR) analysis for the EPDM from the prior work. Slabs that were press-cured 30 minutes at $160^{\circ} \mathrm{C}$ by the University of Akron were also received and were used for a comparison of 
Table 1. EPDM Formulation, SS384725

\begin{tabular}{lr}
\hline Ingredient & PHR \\
\hline Nordel 1440 & 100 \\
Zinc Oxide & 5 \\
N-990 Carbon Black & 40 \\
N-539 Carbon Black & 25 \\
DiCup 40C & 12 \\
Vanox ZMTI & 2 \\
Rocryl 910 & 10 \\
\hline
\end{tabular}

extractables by Soxhlet extraction. These slabs were then postcured in either air or a vacuum for 2,4 , or 6 hours at $182^{\circ} \mathrm{C}$. The Akron slabs were also postcured for 8 and 24 hours to determine the magnitude of any damage caused from postcuring for longer times by using Soxhlet extraction.

Table 2 contains some of the properties analyzed to optimize postcure time and to determine whether an air or vacuum postcure was preferred. The hardness value is slightly increased because of postcuring, but this property shows no significant difference between an air or a vacuum postcure for up to 6 hours. The values for $t$ from the rheometrics mechanical spectrometer (RMS)

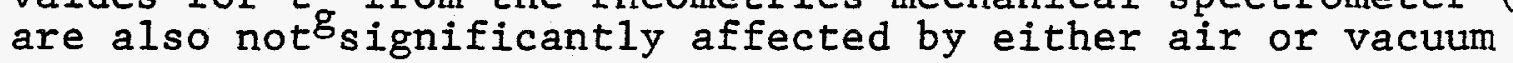
postcure.

Table 2 contains the individual compression set values after aging 70 hours at $125^{\circ} \mathrm{C}$, and Figure 1 plots the average of these compression set values. Compression set was performed at 25-percent compression according to ASTM-D-395, Method B. Postcuring causes a beneficial decrease in compression set; however, both vacuum and air postcuring improve the compression set to approximately the same range of 4 to 7 percent after 2 to 4 hours of postcure. This is generally a very low compression set for EPDM formulations, and postcuring is recommended on this basis alone.

Figure 2 contains the weight percent extractables after Soxhlet extraction in toluene for 24 hours. Again, postcuring in air and vacuum produced approximately the same change. The Akron molded slabs appear to be slightly more undercured than the KCD molded slabs, as indicated by the larger amount of unbound material extracted. Also, postcure times longer than 6 hours in air can be seen to cause degradation in the EPDM, based on the data for the Akron slab. 
Table 2. Effects of Air Versus Vacuum Postcure

\begin{tabular}{|c|c|c|c|c|c|c|c|}
\hline \multirow[b]{2}{*}{ Property } & \multirow[b]{2}{*}{ No Postcure } & \multicolumn{3}{|c|}{$\begin{array}{l}\text { Air Postcure, } \\
\text { Hours at } 182^{\circ} \mathrm{C}\end{array}$} & \multicolumn{3}{|c|}{$\begin{array}{l}\text { Vacuum Postcure, } \\
\text { Hours at } 182^{\circ} \mathrm{C}\end{array}$} \\
\hline & & 2 & 4 & 6 & 2 & 4 & 6 \\
\hline Hardness (Shore A) & 78 & 80 & 80 & 81 & 79 & 80 & 79 \\
\hline $\begin{array}{l}\text { Compression Set, } \\
70 \mathrm{~h} \text { at } 125^{\circ} \mathrm{C} \\
(\%)\end{array}$ & $10.7,10.7$ & $6.9,6.4$ & $4.1,4.0$ & -- & $4.1,3.3$ & $4.9,4.9$ & - \\
\hline $\begin{array}{l}T_{g} \text { by RMS } \\
\text { at max. G" } \\
\left({ }^{\circ} \mathrm{C}\right)\end{array}$ & -53 & -52 & -52 & -52 & -51 & -54 & -51 \\
\hline
\end{tabular}

Lastly, Figure 3 contains the weight percent swell after immersion for 3 days in toluene. The error bars represent the 95-percent confidence limits about the mean. As expected, postcuring reduces the swell because of additional crosslinking. There is essentially no difference after postcuring 2 hours in air or vacuum, and the vacuum postcuring shows very little change for up to 6 hours in the oven. However, postcuring in air shows a slight degradation after 4 hours; after 6 hours, the divergence between air and vacuum postcuring is statistically significant.

The data indicate that a postcure is warranted and that postcure times should be limited to 2 to 4 hours. Longer postcure times do not produce any significant improvement in properties and may be detrimental to the performance of the rubber. Vacuum postcure is preferred where practical because of the degradation in air shown by solvent swell and also because of visual effects. Air postcured slabs had a dull matte appearance and surface pitting after postcure, whereas the vacuum postcured slabs had no such areas. The surface blemishes were very evident in areas of finger contact. However, based on subsequent physical property and stress relaxation testing, the degradation appeared limited only to the surface.

The surface attack during air postcure was traced to the antioxidant being used: zinc 2-mercaptotolylimidazole (Vanox 2MTI). Replacing this antioxidant with polymerized 2,2,4-trimethy1-1,2-dihydroquinoline (Flectol $\mathrm{H}$ ) eliminated this problem. Even though vacuum postcuring produced no visual defects, the surface attack from air postcuring warranted a change because of potential applications where vacuum postcure would be impractical or unnecessary. Therefore, the EPDM 


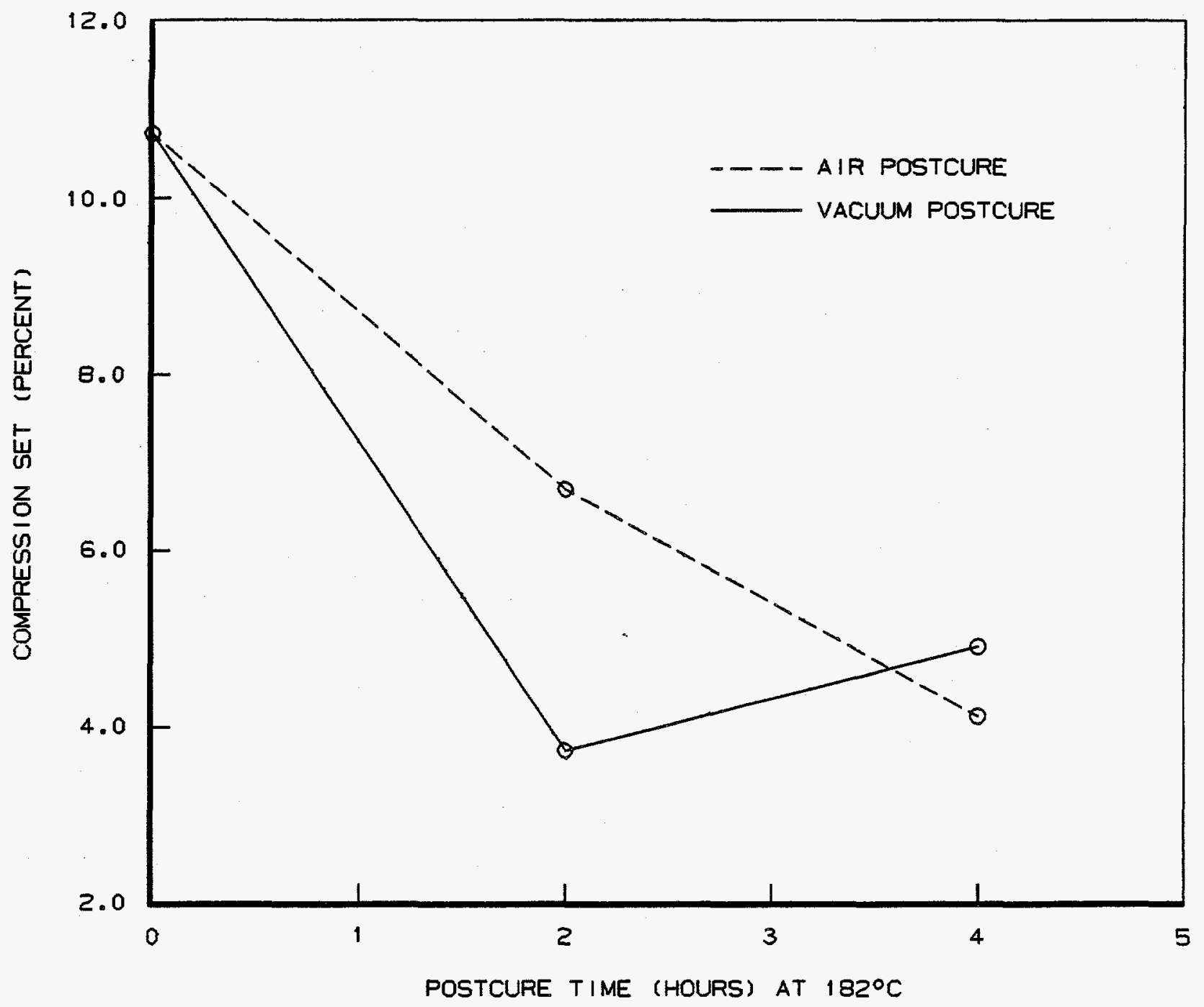

Figure 1. Compression Set Percent Versus Postcure Time of Slabs Press-Cured 10 Minutes at $177^{\circ} \mathrm{C}$

formulation has been changed to call out the new antioxidant. The effects of Flectol $\mathrm{H}$ on the EPDM formulation have been evaluated in other projects. Generally, Flectol H causes a slight retardation of cure by consuming some of the free radicals generated when the peroxide decomposes. The main effect is a slightly lower hardness value; however, this change is unimportant when compared with the improvement Flectol H imparts in aging behavior and visual appearance after postcure.

Table 3 shows the change in properties for a 2-hour postcure in air at $182^{\circ} \mathrm{C}$. All the EPDM batches to date have been vacuum postcured. This table is provided for reference if an air postcure would be used. 


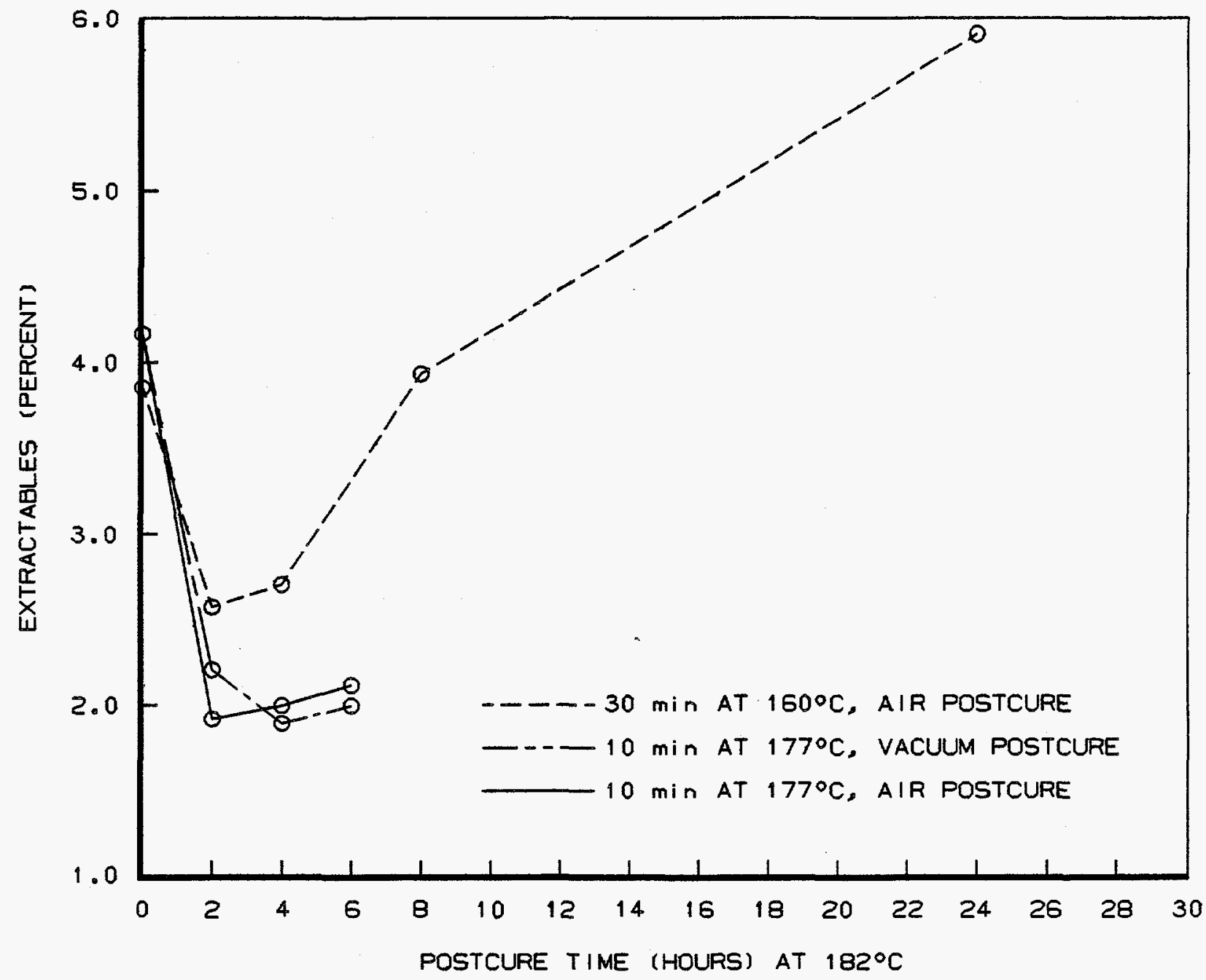

Figure 2. Effect on Extractables With Press-Cure and Postcure Conditions

\section{Stress Relaxation Study}

The stress relaxation behavior test of the butyl and EPDM was performed under compression and was used to compare the relative aging behavior between the two materials. The stress relaxation test procedure consists of stacking three disks (approximately $1.575 \mathrm{~mm}$ thick by $12.7 \mathrm{~mm}$ diameter) for each of three stress relaxation fixtures and then compressing the stacked samples within the fixtures by approximately 25 percent. One to 2 minutes after compressing the samples, the initial resultant compressive force is measured. The fixtures are then placed in an oven at the desired aging temperature. Periodically, the fixtures are removed from the oven and allowed to cool to room 


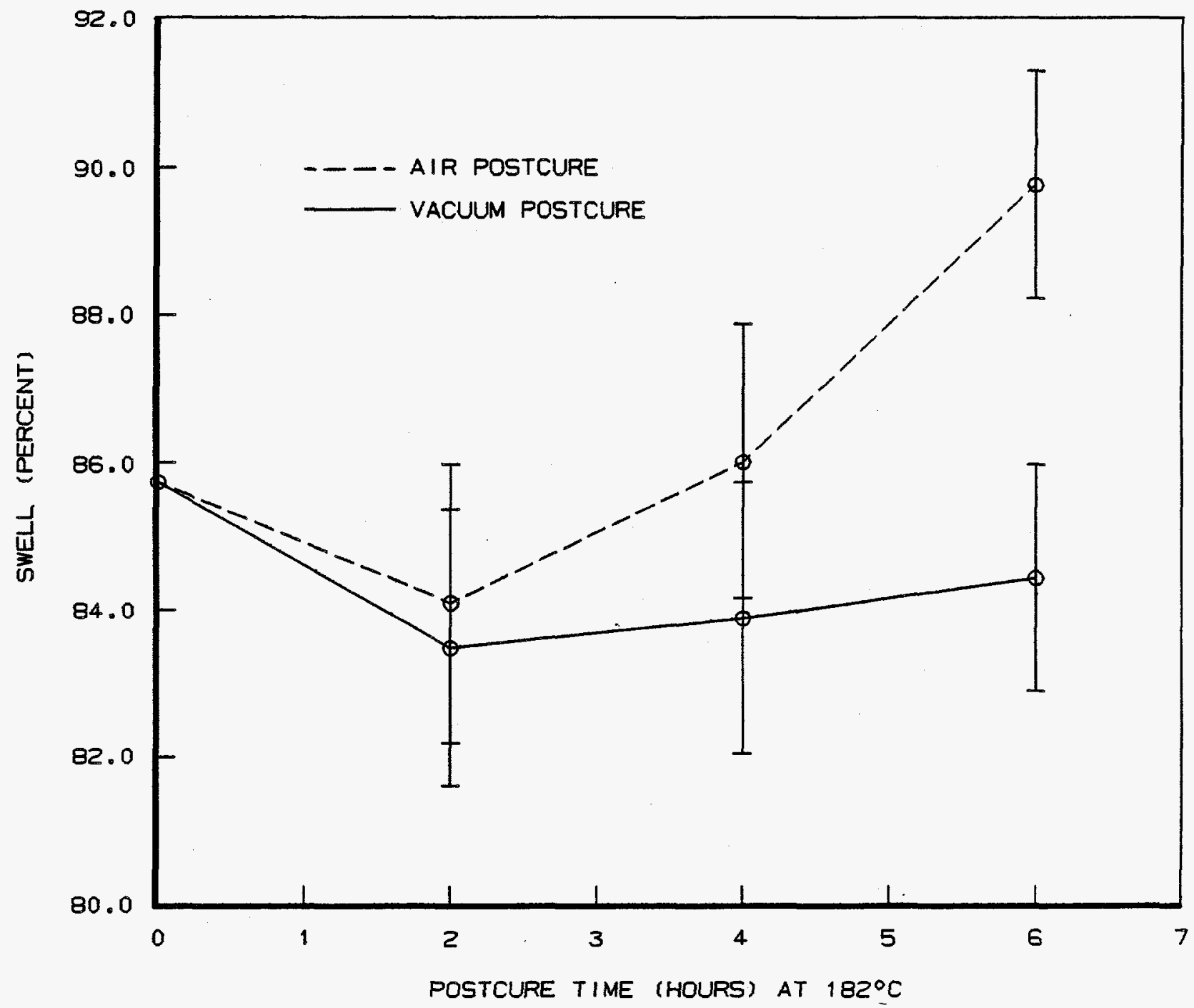

Figure 3. Weight Percent Swell in Toluene Versus Postcure Time of Slabs Press-Cured 10 Minutes at $177^{\circ} \mathrm{C}$

temperature for approximately 3 to 4 hours, after which the resultant compressive force is again measured. The amount of decay in force is the stress relaxation, and any permanent decrease from original sample height is the compression set. At the completion of the test, the compression set for the three samples is measured 30 minutes after the material is removed from the fixtures.

Figure 4 shows a stress relaxation fixture, and Figure 5 shows the force measuring instrument with a fixture in place ready to 
Table 3. Physical Properties Before and After a Postcure of 2 Hours at $182^{\circ} \mathrm{C}$ in $\mathrm{Air}$

\begin{tabular}{lcc}
\hline Property & No Postcure & Postcure \\
\hline Hardness (Shore A) & 78 & 80 \\
$100 \%$ Modulus (psi) & 1370 & 1400 \\
Tensile Strength (psi) & 1780 & 1500 \\
Elongation (\%) & 124 & 108 \\
Compression Set, 7 h at $125^{\circ} \mathrm{C}(\%)$ & $10.7,10.7$ & $6.9,6.4$ \\
\hline
\end{tabular}

be measured. This equipment is manufactured by $\mathrm{H}$. W. Wallace \& Co. Ltd., Croydon, England. The force measurement is automatically displayed after an electrical contact is broken within the fixture, signifying that the applied force is equal to the force exerted by the test sample. This method results in negligible sample deformation during measurement.

Originally, the materials were to be aged for 1 year at $60^{\circ} \mathrm{C}$, 6 months at $70^{\circ} \mathrm{C}$, and 3 months at $80^{\circ} \mathrm{C}$. However, there was so little difference in stress relaxation of the EPDM between 70 and $80^{\circ} \mathrm{C}$, it was decided not to run stress relaxation at $60^{\circ} \mathrm{C}$. Instead, the stress relaxation data for 70 and $80^{\circ} \mathrm{C}$ were collected beyond the original time periods of 6 and 3 months, respectively.

The EPDM formulation tested for stress relaxation used Vanox ZMTI as the antioxidant and was postcured in air. The stress relaxation testing was begun before the antioxidant was changed to Flectol H. Even though vacuum postcure is preferred, the air postcure was chosen to represent a worst case condition for the EPDM. The postcure optimization data from the previous section indicate that the stress relaxation behavior for a vacuum postcure should be equivalent to superior for an air postcure. The use of Flectol $\mathrm{H}$ should also provide stress relaxation behavior that is equivalent or superior to a formulation using Vanox ZMTI. These conclusions are supported by aging behavior performed in other projects.

Figures 6 and 7 compare the stress relaxation behavior between butyl and the EPDM at 70 and $80^{\circ} \mathrm{C}$, respectively. The stress relaxation curves are expressed as a ratio of the stress remaining, $F(t)$, divided by the initial closure force, $F(0)$. 


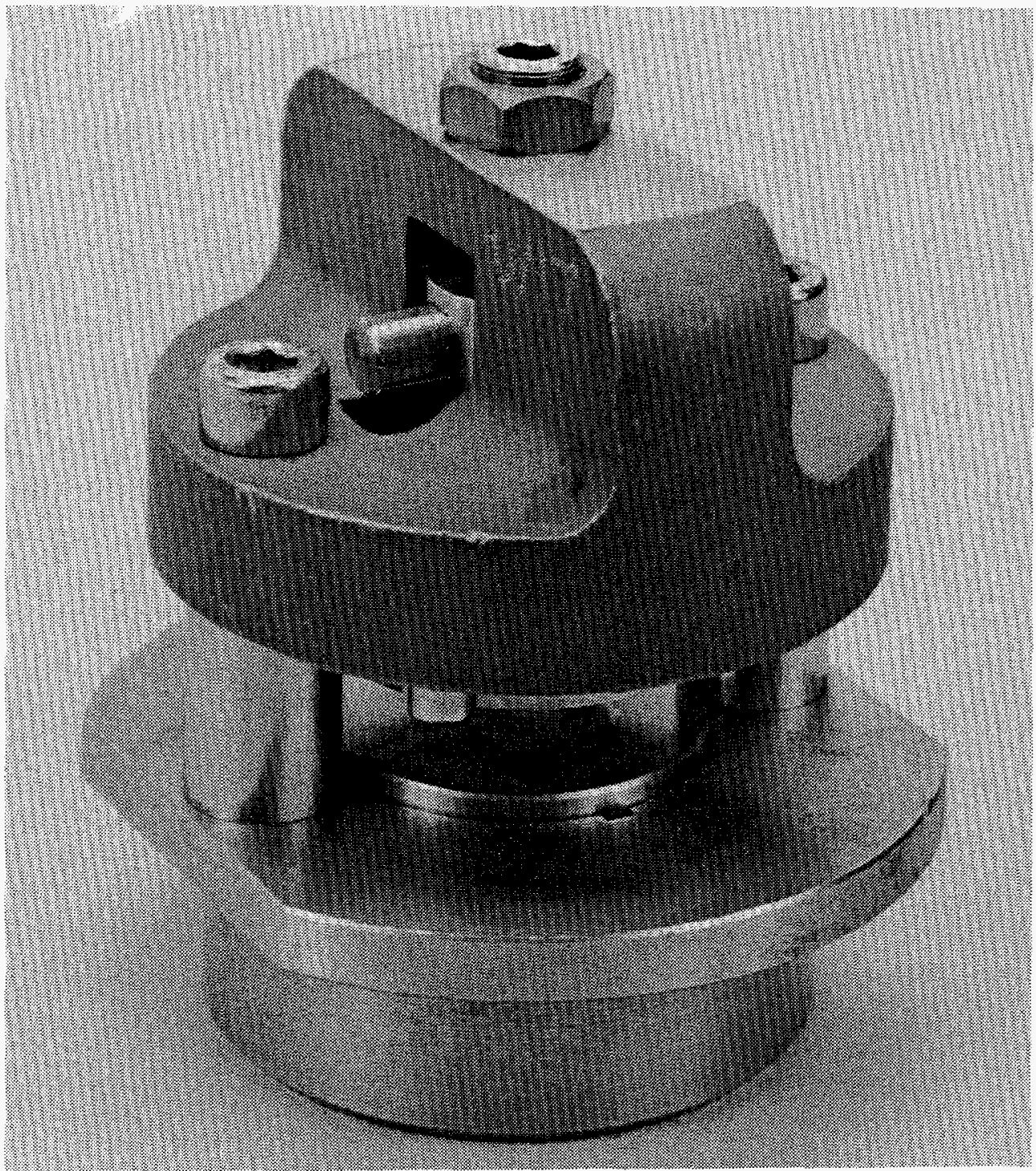

Figure 4. Compression Stress Relaxation Fixture

Both figures show that the EPDM has outstanding stress relaxation behavior when compared with the butyl. The stress relaxation for the EPDM is very stable and exhibits essentially linear decay that indicates only physical relaxation processes are predominant for the 616-day time period of the test. Butyl, on the other hand, shows chemical relaxation effects by the nonlinear behavior of the stress relaxation.

The EPDM-1 curve (Figure 7) represents material tested in new fixtures. The standard deviation among the three fixtures was felt to be higher than preferred; therefore, a second set of 




Figure 5. Force Measuring Instrument With Fixture Ready to Be Measured 


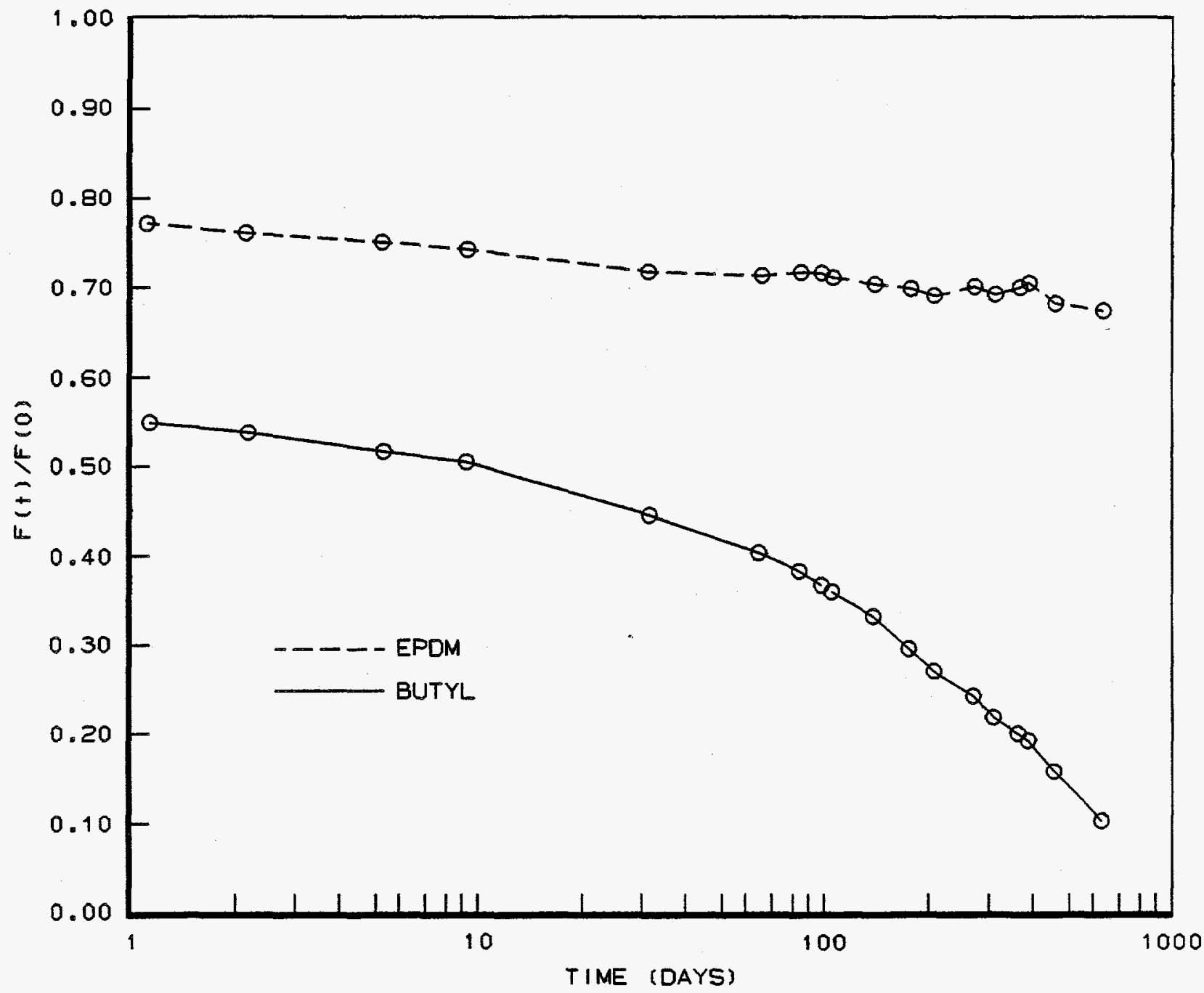

Figure 6. Stress Relaxation of Butyl and EPDM After Aging at $70^{\circ} \mathrm{C}[\mathrm{F}(0)=$ initial closure force; $F(t)=$ closure force at time $(t)]$

samples, EPDM-2, was begun to improve the accuracy by using fixtures that had produced successful results in the past.

Although the standard deviation did improve from 4.1 to $2.3 \%$ for the first day, the average initial closure force decreased from 537 to 437 newtons for material out of the same slab and compressed by the same amount. The cause of this difference was never determined. Nevertheless, the two EPDM stress relaxation curves are essentially equivalent and are decaying at the same rate. It should also be noted that the initial modulus of the EPDM was twice as large as for the butyl. The average initial closure force for EPDM-1 was 537 newtons, whereas the closure 


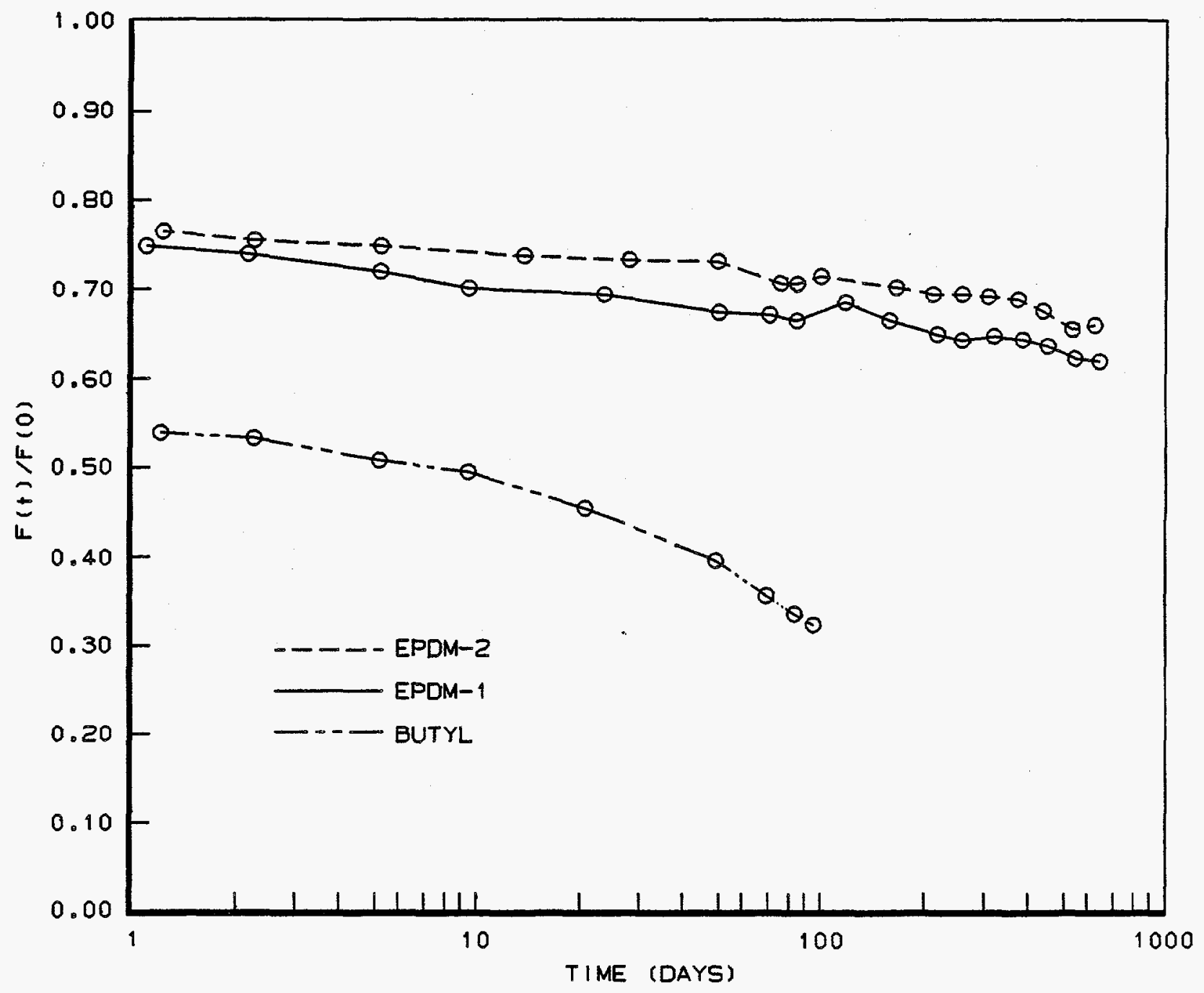

Figure 7. Stress Relaxation of Butyl and EPDM After Aging at $80^{\circ} \mathrm{C}[\mathrm{F}(0)=$ initial closure force; $F(t)=$ closure force at time $(t)]$

force for the butyl material was 256 newtons. Consequently, the force necessary to squeeze an EPDM 0-ring will be greater than for a buty1 o-ring.

Because the fixtures are removed from the oven and allowed to cool at room temperature before measurement, there was concern that this periodic thermal cycling would affect the stress relaxation behavior. Therefore, three additional fixtures each for the butyl and EPDM- 1 materials aged at $80^{\circ} \mathrm{C}$ were allowed to remain in the oven continuously and were only removed for measurement at the end of the aging period. Table 4 contains the 
Table 4. Stress Relaxation of Intermittent and Continuously Aged Butyl and EPDM Expressed as a Percent of Initial Stress

\begin{tabular}{|c|c|c|c|c|}
\hline \multirow{2}{*}{$\begin{array}{l}\text { Aging } \\
\text { Temperature }\left({ }^{\circ} \mathrm{C}\right)\end{array}$} & \multirow[b]{2}{*}{ Material } & \multirow{2}{*}{$\begin{array}{l}\text { Aging } \\
\text { Time } \\
\text { (days) }\end{array}$} & \multicolumn{2}{|c|}{ Average Stress Relaxation \pm Sigma } \\
\hline & & & Intermittent & Continuous \\
\hline 70 & Buty1 & 616 & $10.6 \pm 0.9$ & $-\infty$ \\
\hline 70 & EPDM & 616 & $67.6 \pm 1.7$ & $-\infty$ \\
\hline 80 & ButyI & 93 & $32.4 \pm 2.6$ & $32.6 \pm 2.1$ \\
\hline 80 & EPDM-1 & 616 & $61.4 \pm 3.3$ & $64.3 \pm 1.7$ \\
\hline 80 & EPDM-2 & 616 & $66.0 \pm 2.5$ & $-\infty$ \\
\hline
\end{tabular}

stress relaxation values plus or minus the standard deviation measured at the end of the aging period for the intermittent and continuously aged materials. The data indicate that removing the fixtures for measurement had no effect on the stress relaxation behavior.

Table 5 contains the compression set values plus or minus the standard deviation measured at the completion of the stress relaxation testing. As with the stress relaxation data, these results show that there is no difference between the intermittent and continuously aged samples. As expected, the EPDM is also shown to have much better compression set resistance than the butyl material.

Analysis of variance at the $\alpha=0.05$ level indicates that the compression set value for EPDM-2 is slightly larger than for EPDM- 1 but that the values for stress relaxation are indistinguishable. As with the difference in initial closure force for EPDM-1 and EPDM-2, the cause of this difference in compression set resistance is unknown; however, the overall aging behavior of the EPDM is clearly superior to the butyl.

Based on its superior stress relaxation behavior, the EPDM is recommended for use instead of the butyl. The EPDM also has a higher permeability than the butyl. For sealing applications where permeability is important, this higher permeability should be taken into consideration when the EPDM is used to replace o-rings that were made with butyl. 
Table 5. Compression Set of Intermittent and Continuously Aged Butyl and EPDM After Stress Relaxation Testing

\begin{tabular}{|c|c|c|c|c|}
\hline \multirow{2}{*}{$\begin{array}{l}\text { Aging } \\
\text { Temperature }\left({ }^{\circ} \mathrm{C}\right)\end{array}$} & \multirow[b]{2}{*}{ Material } & \multirow{2}{*}{$\begin{array}{l}\text { Aging } \\
\text { Time } \\
\text { (days) }\end{array}$} & \multicolumn{2}{|c|}{ Average Compression Set \pm Sigma } \\
\hline & & & Intermittent & Continuous \\
\hline 70 & Buty1 & 616 & $80.3 \pm 0.6$ & -- \\
\hline 70 & EPDM & 616 & $23.3 \pm 0.3$ & -- \\
\hline 80 & Buty1 & 93 & $35.8 \pm 2.6$ & $37.2 \pm 0.9$ \\
\hline 80 & EPDM-1 & 616 & $29.9 \pm 1.0$ & $29.9 \pm 1.3$ \\
\hline 80 & EPDM-2 & 616 & $33.3 \pm 3.1$ & --- \\
\hline
\end{tabular}

\section{Shore A EPDM Evaluation}

A condition of the original contract with Dr. David Winkler, Institute of Polymer Science, The University of Akron, was to provide an EPDM formulation with a nominal hardness value of 70 Shore A. The actual hardness was closer to 80 Shore A because he was using an out-of-calibration durometer. Dr. Winkler reformulated the EPDM to achieve a 70 Shore $A$ hardness and provided test slabs and uncured material for testing. Table 6 contains the new formulation, and the full report from Akron is contained in the appendix of this report. The original EPDM formulation was modified slightly by reducing the level of curatives (Varox 40C and Rocryl 910) and by adding a small amount of polybutadiene polymer.

Table 7 shows a comparison of the physical properties for different cure conditions. The KCD value of 74 for hardness is lower than the original EPDM formulation but higher than the hardness reported by the University of Akron. By replacing the antioxidant, Vanox ZMTI, with the new antioxidant, Flectol H, the hardness should be reduced a few more points. More lots would be needed to determine if the natural hardness is in the 65 to 75 Shore A range as desired. The compression set after postcure is slightly higher than the original EPDM formulation but is still felt to be an excellent value.

Stress Relaxation of the 70 Shore A EPDM

Figure 8 adds the new 70 Shore A EPDM formulation's stress relaxation behavior to Figure 7 for comparison with the other materials. The compression set measured after the stress 
Table 6. 70 Shore A EPDM Formulation

\begin{tabular}{lr}
\hline Ingredient & PHR \\
\hline Nordel 1440 & 100 \\
Cis-1, 4-polybutadiene & 5 \\
Zinc Oxide & 5 \\
N-990 Carbon Black & 40 \\
N-539 Carbon Black & 25 \\
Vanox 40C & 8 \\
Vanox ZMTI & 2 \\
Rocry 910 & 5 \\
\hline
\end{tabular}

relaxation testing was as follows: time, 306 days; temperature, $80^{\circ} \mathrm{C}$; and average compression set ( \pm sigma), $33.1 \pm 0.3$. The new EPDM formulation was also postcured in air to represent a worst case condition. The stress relaxation behavior of the new EPDM is slightly worse than the original formulation. The new formulation represents a promising lower durometer rubber that would require further characterization before use.

\section{ACCOMPLISHMENTS}

This study was composed of three parts: a postcure study to optimize final properties, an accelerated aging study to compare the stress relaxation behavior of two elastomers under compression, and a cursory evaluation of a new 70 Shore A EPDM supplied by the University of Akron. The materials tested for the postcure and accelerated aging studies were a butyl and an EPDM elastomer to be used for 0 -rings on a weapon assembly. The butyl compound was B612-70, which is a proprietary formulation from Parker Seal Group, O-Ring Division, and the EPDM formulation tested was SS384725.

The postcure study evaluated changes in certain physical properties, solvent swell, and extractables after an air or vacuum postcure at $182^{\circ} \mathrm{C}$. Postcuring is recommended because of the improvement in compression set to values lower than $10 \%$ after 70 hours at $125^{\circ} \mathrm{C}$. The optimum postcure for the EPDM was found to be 2 to 4 hours at $182^{\circ} \mathrm{C}$ in a vacuum.

Stress relaxation testing was performed at 70 and $80^{\circ} \mathrm{C}$ for a maximum of 616 days. Removing the samples from the oven for measurement caused no significant difference in stress relaxation behavior from samples that were allowed to remain in the oven continuously. The EPDM was shown to have superior aging 
Table 7. Physical Properties of 70 Shore A EPDM Rubber

\begin{tabular}{|c|c|c|c|}
\hline Property & Akron & $\mathrm{KCD}$ & $\mathrm{KCD}$ \\
\hline Press-Cure & $31.5 \mathrm{~min}$. at $160^{\circ} \mathrm{C}$ & $15 \mathrm{~min}$ at $166^{\circ} \mathrm{C}$ & $15 \mathrm{~min}$ at $166^{\circ} \mathrm{C}$ \\
\hline Postcure & None & None & $\begin{array}{l}4 \mathrm{~h} \text { at } 182^{\circ} \mathrm{C} \\
\text { in a vacuum }\end{array}$ \\
\hline Hardness (Shore A) & 70 & 73 & 74 \\
\hline $100 \%$ Modulus (psi) & 975 & 759 & 892 \\
\hline $\begin{array}{l}\text { Tensile strength } \\
\text { (psi) } \\
\text { (MPa) }\end{array}$ & $\begin{array}{r}1890 \\
13.0\end{array}$ & $\begin{array}{r}1820 \\
12.6\end{array}$ & $\begin{array}{r}1850 \\
12.8\end{array}$ \\
\hline Elongation (\%) & 155 & 198 & 192 \\
\hline $\begin{array}{l}\text { Compression Set, } \\
70 \mathrm{~h} \text { at } 125^{\circ} \mathrm{C}(\%)\end{array}$ & 8.0 & $20.5,23.0$ & $12.5,7.9$ \\
\hline
\end{tabular}

characteristics compared to the butyl and is recommended for use instead of the butyl material.

The original request for a 70 shore A durometer EPDM from the University of Akron was received for evaluation. The lower durometer was achieved by adding a small amount of polybutadiene rubber and by reducing the level of curatives. Physical properties for this compound are satisfactory, and the stress relaxation results at $70^{\circ} \mathrm{C}$ are only slightly inferior to SS384725. 


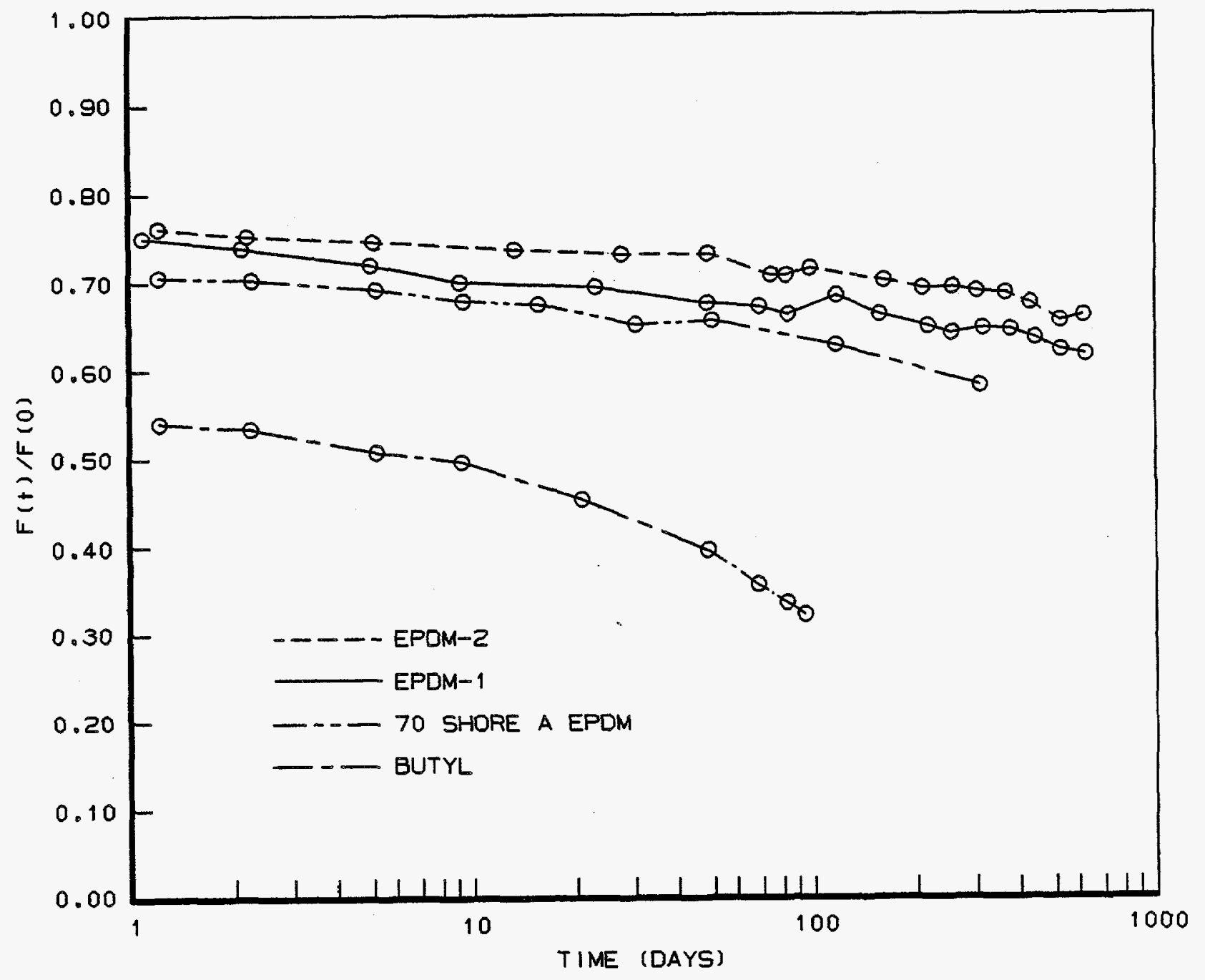

Figure 8. Stress Relaxation of Butyl, the Original EPDM Formulation, and the 70 Shore A EPDM Formulation After Aging at $80^{\circ} \mathrm{C}$ $[F(0)=$ initial closure force; $F(t)=$ closure force at time $(t)]$ 


\section{Appendix}

DEVELOPMENT OF EPDM COMPOUND

BY THE UNIVERSITY OF AKRON 


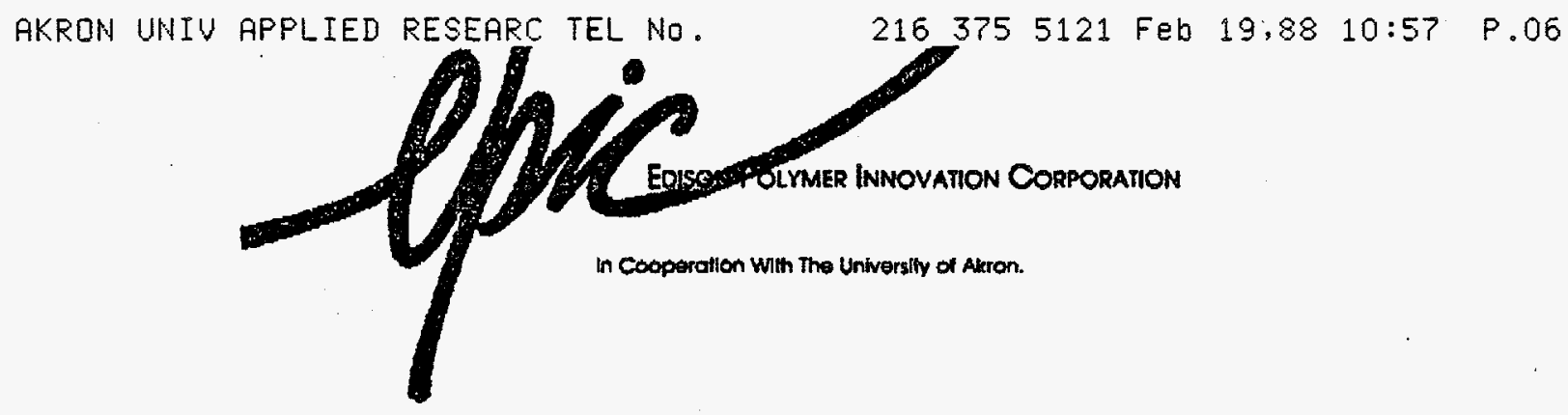

Institute of Polymer Science

Applied Research

Phone (216) 375-7513

January 5,1988

A.liled Bendix Aerospace

Bendix Kansas City Division

2100 East 95th Street

Kansas City, Missouri 64131

Attn: Mr. Mark wilson

Dept. $814 W-X D 44$

Reference: P. $0.017 D 218068$

Dear Mr. Wilson:

The development of an EPDM compound to meet your specifications has been completed. The formulation for this compound is shown below.

\begin{tabular}{l} 
Ingredient \\
\hline Nordel 1440 \\
Cis-1.4 polybutadiene \\
N-990 Carbon Black \\
N-539 Carbon Black \\
Varox $40 C$ \\
Vanox ZMrI \\
Zinc Oxide \\
RocryI 910
\end{tabular}

\begin{tabular}{l} 
Ingredient \\
\hline Varox $40 \mathrm{C}$ \\
Vanox 2MTI \\
Rocry 1910
\end{tabular}

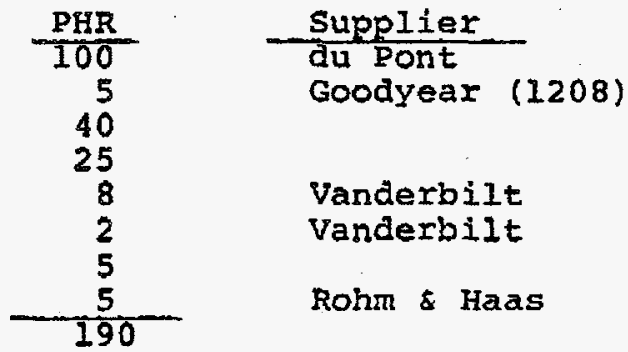

$\frac{\text { Chemical Name }}{40 \% \text { Decumyl Peroxide on } \mathrm{CaCO}_{3}}$
zinc 2-mercaptotolylimidazole
Trimethylolpropane trimethacrylate

The compound was formulated on a two roll rubber mill. A cure temperature of $320^{\circ} \mathrm{F}$ was employed. The cure characteristics were obtained with an oscillating disc rheometer (ODR) at $320^{\circ} \mathrm{F}$. The cure time obtained was 31.5 minutes. Please find enclosed the rheograph of this compound at $320^{\circ} \mathrm{F}$. 
The ethylene/propylene ratio was studied by WMR vsing a Varian 400 megahertz instrument. The ethylene content observed was 94.268 and the propylene content was $5.74 \%$.

Toluene extractions were found to be $7.3 \%$ on an unaged sample. After a post cure of 2 hours at $360^{\circ} \mathrm{F}$, this value was found to be 4.68 .

The specific gravity was observed to be $1.121 \mathrm{~g} / \mathrm{cc}$.

The compression set obtained in accordance with ASTM D-395, Method B was 8.0\%. This test was conducted at $257^{\circ} \mathrm{F}$ for 70 hours.

The shore A haraness observed on vulcanizates of this compound was 70 .

A strip cut Erom a cured tensile slab was immersed in a dry ice/methanol bath at $-80^{\circ} \mathrm{C}$ and left there for 1 hour. The test strip was grasped with a pair of tongs and then bent back on itself without cracking or breaking. The Tg of this compound appears to be below $-80^{\circ} \mathrm{C}$ thus meeting your requirement.

The physical properties of this vulcanizate are shown below.

$\begin{array}{lr}\text { Tensile Strength, psi } & 1890 \\ \text { loos Modulus, psi } & 975 \\ \text { Elongation, \& } & 155 \\ \text { Die C Tear Strength, lbs/in } & 160\end{array}$

Should you have any questions concerning the above, please feel free to contact me at your convenience.

Yours very truly,

David s. Winkler

Manager Applied Research

Ib 


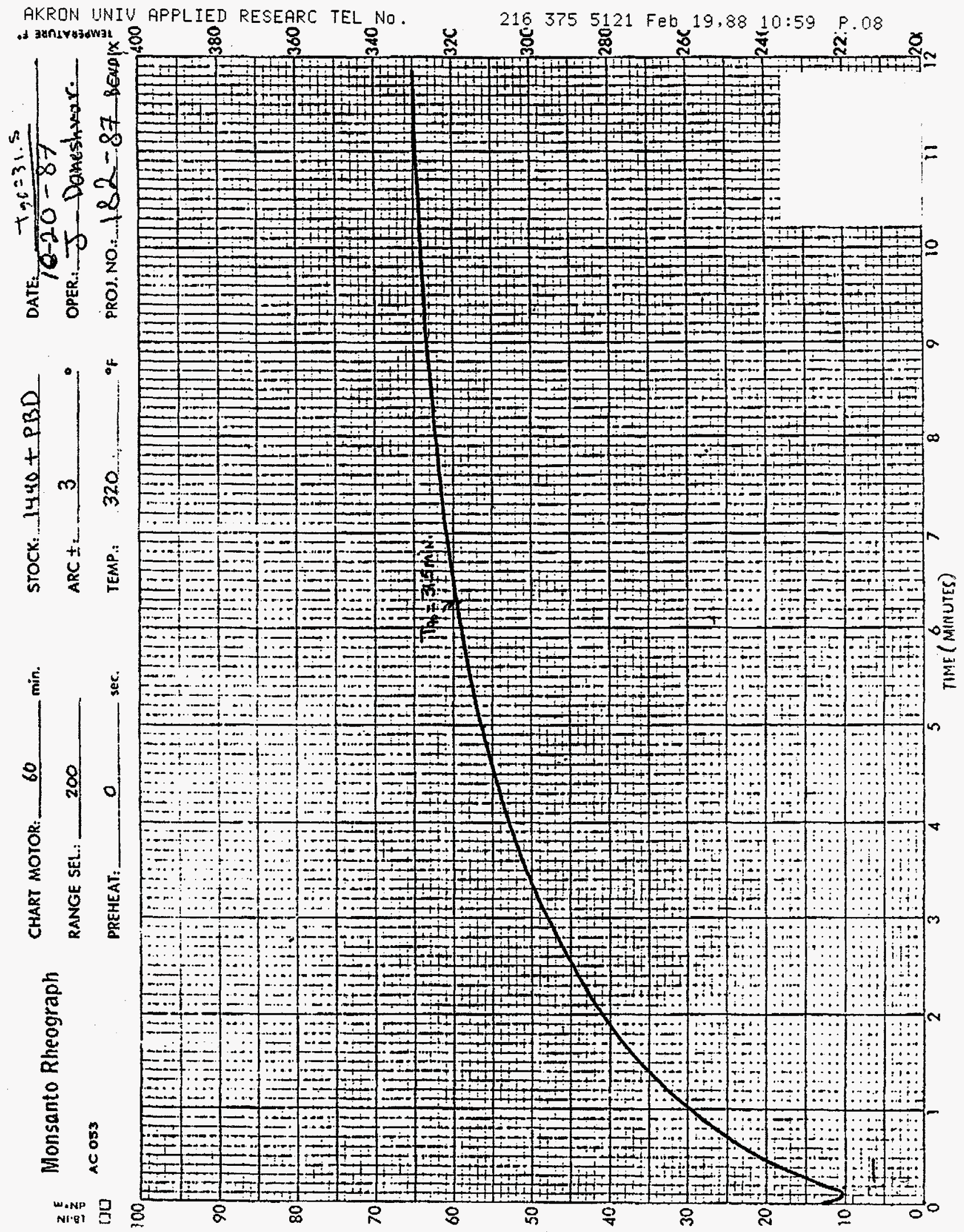

